\title{
Mechanical and microstructure analysis of AA6061 and Ti6Al4V fiber laser butt weld
}

\author{
Giuseppe Casalino, $^{1, \text { a) }}$ Sonia D’Ostuni ${ }^{\text {, , b) }}$ Pasquale Guglielmi ${ }^{1, \text { c) }}$ Paola Leo ${ }^{\text {, d) }}$ \\ Michelangelo Mortello, ${ }^{3, \text { e) }}$, Gianfranco Palumbo, 1, f) , Antonio Piccininni, ${ }^{1, g}$ ), \\ ${ }^{1}$ DMMM, Politecnico di Bari, Viale Japigia, 182, 70124 Bari, Italy \\ ${ }^{2}$ Dipartimento di Ingegneria dell'Innovazione, University of Lecce, Via per Monteroni, Lecce, Italy \\ ${ }^{3}$ Welding Engineering Research Centre, Building 46, Cranfield University, Bedfordshire, MK43 OAL, United \\ Kingdom
}

\begin{abstract}
Dissimilar metal welding involves the joining of two or more different pure metals or alloys, usually by melting and mixing and often with the addition of filler metal. There are several types of dissimilar metal welds including stainless steel, either as base metal or as filler metals. Dissimilar metal joints have distinctive features because of differences in the chemical composition of base metal and filler material. Their alloying elements will diffuse intensely during welding. The structures near the fusion line are very complex. Despite of great potentiality in aircraft and automotive industries, dissimilar joining of hybrid Al-Ti structures is often challenging because of the unavoidable formation of brittle intermetallic compounds, mixing of molten phases, and significant differences in material properties. In this work, dissimilar $2 \mathrm{~mm}$ thickness AA6000 and Ti6Al4V butt joints were produced by shifting an $\mathrm{Yb}$ fiber laser beam on the upper surface of the Ti sheet. Neither filler wire nor groove preparation was adopted. Different working conditions and seam shapes were assessed. The welds were characterized in terms of metallurgical and mechanical behaviors.
\end{abstract}

Key-words: fiber laser welding, dissimilar weld, Mechanical and microstructure properties.

\section{INTRODUCTION}

Modern industries such as aeronautics, automotive, and power generation call for high performance products, which integrate an increased number of functions and properties like lightweight and recyclability and warrant efficiency and versatility. As one single material fails often to meet those requirements, a combination of two or more materials can satisfy a specific need of those industries [1].

Published by Elsevier. This is the Author Accepted Manuscript issued with: Creative Commons Attribution Non-Commercial No Derivatives License (CC:BY:NC:ND 4.0). The final published version (version of record) is available online at DOI:10.1016/j.ijleo.2017.08.138

Please refer to any applicable publisher terms of use. 
Joining processes are largely exploited in manufacturing traditional and innovative products. Welding is very popular in the manufacturing industry. Both fusion and solid state welding is used for a variety of materials and products [2]. Among fusion welding techniques, the laser has gained a prominent position as an autogeneous fusing source for metals joining [3]. When the laser works in the key-hole mode has energy as large as $10^{13} \mathrm{~W} / \mathrm{m}^{2}$. That high energy vaporizes a cavity and melts the surrounding material. As an example, thick plates of structural steel can be jhoined by laser welding [4].

Compared with other fusion techniques, fiber laser welding can be considered as a desirable thermal source for controlling interfacial reaction layer, thanks to its locally restricted high energy input and high process speed [5]. Lee et al. demonstrated that the combination of high welding speed and high energy density could suppress the growth of the intermetallic zone [6]. Laser welded dissimilar Al-Ti joints were performed by shifting the source on the substrate of the Al side, which presents a lower melting point [7]. Casalino et al studied the shifted welding of Magnesium to stainless steel steels [8]. As examined by Khoshhal et al., when a Ti sheet is immersed in an Al molten bath, both $\mathrm{Ti}$ and $\mathrm{Al}$ diffuse into each other [9]. Chen et al. observed cracks initiation and propagation to find the interfacial reaction layer morphologies that enhance mechanical properties [10]. Song et al. found that, with increasing of the laser offset, the maximum temperature at the interface becomes lower and the time for diffusion of Ti atoms decreases giving a thinner layer [11]. Tomashchuk et al. demonstrated that when the laser beam is focused on the $\mathrm{Al}$ sheet and the cooling gradient is maximized. The inter-diffusion and mixing of melted materials is almost avoided [12]. Vaidya et al. performed laser welded dissimilar joints by inserting the Ti sheet into profiled $\mathrm{Al}$ sheet to favor the coupling [13]. Faraji et al. explored the capability of the hybrid laser-arc welding in comparison with lone laser welding for AA2198 aluminum alloy [14]. The quality of laser weld has been studied and modelled with different numerical techniques like the computational intelligence $[15,16]$. Olabi et al. found the optimal condition for dissimilar steels laser butt weld [17].

In this paper, the titanium side of a dissimilar Ti6Al4V and AA6061 butt weld was irradiated with a laser beam in the proximity of the metals interface. A stable keyhole welding established in the titanium and the heat was transmitted to the $\mathrm{Al}$ side without mixing the liquid phases of the two metals, which led to the formation of a very thin and regular interface along the weld centerline and avoiding porosity in the aluminum. The metallurgical bonding that develops during the process and the mechanical properties of the weld were evaluated. The microhardness was measured in the cross section of the weld and the strain values in the tensile direction were registered by a non-contact and material-independent measuring system based on digital image (ARAMIS).

\section{EXPERIMENTAL SET-UP AND MATERIALS}

Dissimilar assemblies between Ti4V6Al and AA6061 were realized in butt configuration. The size of the sheets was $100 \mathrm{~mm}$ length by $50 \mathrm{~mm}$ width by $2 \mathrm{~mm}$ thickness. Despite the major difference in the tensile properties between the two materials, the weld was performed by adopting the same thickness for both plates. Such a choice was 


\begin{tabular}{llllllllllll}
\hline Al & $\mathrm{Si}$ & $\mathrm{Fe}$ & $\mathrm{Cu}$ & $\mathrm{Mn}$ & $\mathrm{Mg}$ & $\mathrm{Cr}$ & $\mathrm{Zn}$ & $\mathrm{Ti}$ & $\begin{array}{l}\text { Other } \\
\text { Each }\end{array}$ & Other
\end{tabular}

consistent with the main purpose of the investigation, which aimed to explore the process dynamics and the metallurgical bonding.

The welds were produced by an innovative and promising technique, also referred as laser offset welding (LOW), in which the laser source is focused at a certain distance (offset) from the sheets' contact line. This was possible thanks to the selective and highly focused action of a disk laser, which provides for the keyhole regime fusion in the base structure of the irradiated material. A sketch of the welding configuration is shown in Fig. 1.

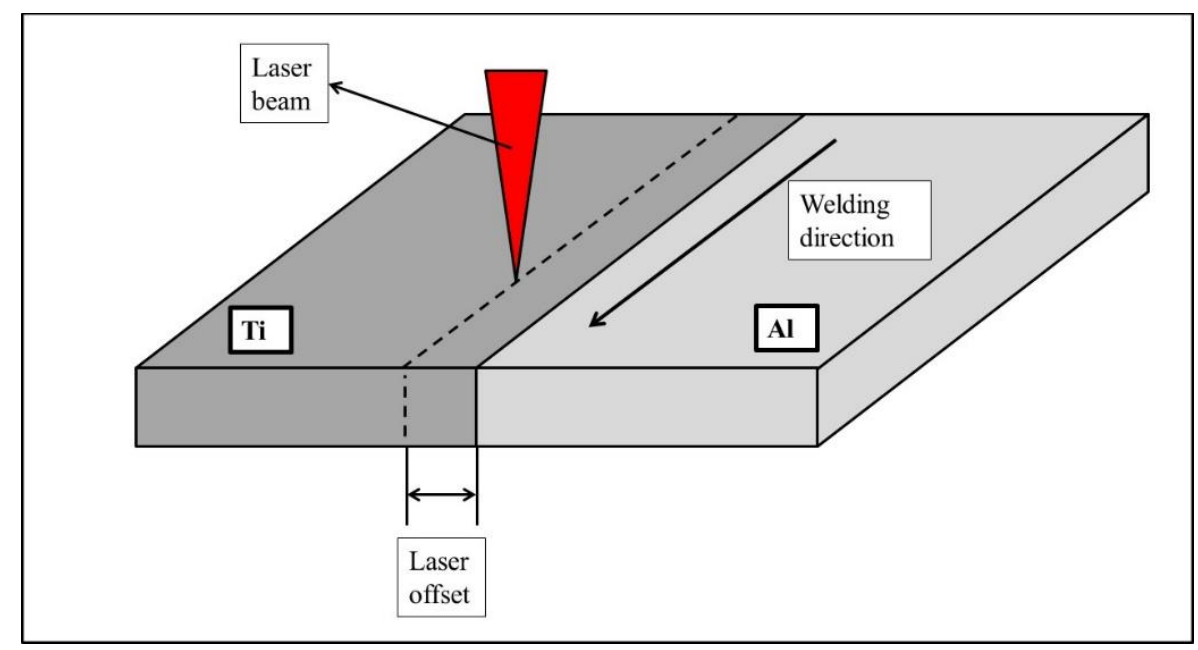

FIGURE 1. sketch of the welding configuration.

An Ytterbium Laser System (IPG YLS-4000) was used. The laser parameters were $1550 \mathrm{~W}$ power, $2.5 \mathrm{~m} / \mathrm{min}$, focus 1 $\mathrm{mm}$ under the sheet surface, offset $0.3 \mathrm{~mm}$. The gap between the sheets was $35 \mu \mathrm{m}$. The clamping devices were applied to the external borders of the sheets.

\begin{tabular}{|c|c|c|c|c|c|c|c|c|c|c|}
\hline & $\mathbf{T i}$ & C & $\mathbf{F e}$ & $\mathbf{N}$ & Al & O & $\mathbf{V}$ & $\mathbf{H}$ & $\mathbf{Y}$ & Other \\
\hline Ti-6Al-4V & balance & $\begin{array}{l}0.08 \\
\max \end{array}$ & $\begin{array}{l}0.03 \\
\max \end{array}$ & $\begin{array}{l}0.05 \\
\max \end{array}$ & $5.5-6.75$ & $0.20 \max$ & $3.5-4.5$ & $\begin{array}{c}0.015 \\
\max \end{array}$ & $\begin{array}{c}0.005 \\
\max \end{array}$ & 0.40 \\
\hline
\end{tabular}

The chemical composition of the base metals is listed in Tables 1 and 2, respectively.

TABLE 1. Ti4V6Al chemical composition.

TABLE 2. AA6061 chemical composition. 


\begin{tabular}{|c|c|c|c|c|c|c|c|c|c|c|c|}
\hline 6061 & balance & $\begin{array}{c}0.40- \\
0.80\end{array}$ & $\begin{array}{l}0.70 \\
\max \end{array}$ & $\begin{array}{c}0.15- \\
0.40\end{array}$ & 0.15 & $\begin{array}{c}0.8- \\
1.2\end{array}$ & $\begin{array}{c}0.04- \\
0.35\end{array}$ & $\begin{array}{l}0.25 \\
\max \end{array}$ & $\begin{array}{l}0.15 \\
\max \end{array}$ & $\begin{array}{l}0.05 \\
\max \end{array}$ & $0.15 \max$ \\
\hline
\end{tabular}

Metallographic specimens were prepared according to standard procedures. Samples were sectioned, mounted in a conductive resin and polished mechanically. Since the weld was made up of two dissimilar materials, a tailored procedure for chemical etching was designed. The chemical etching solution was Keller $\left(95 \mathrm{ml} \mathrm{H}_{2} \mathrm{O}, 2,5 \mathrm{ml} \mathrm{HNO}\right.$, $1,5 \mathrm{ml} \mathrm{HCL}, 1 \mathrm{ml} \mathrm{HF}$ ). The Al side was also electrochemical anodized by the Baker solution. The microstructure was studied by optical microscopy (OM).

Tensile tests were performed on rectangular specimens (total length: $100 \mathrm{~mm}$; free span between the grips: $50 \mathrm{~mm}$ ) extracted from the welded blank to investigate the mechanical properties and the strain behaviour of the welded joint. The set up shown in figure 2 was adopted: tensile tests were assisted by a Digital Image Correlation (DIC) system (GOM-Aramis3D), able to acquire the strain field the specimen is subjected to by means of two 1.3 MPixel sensors.
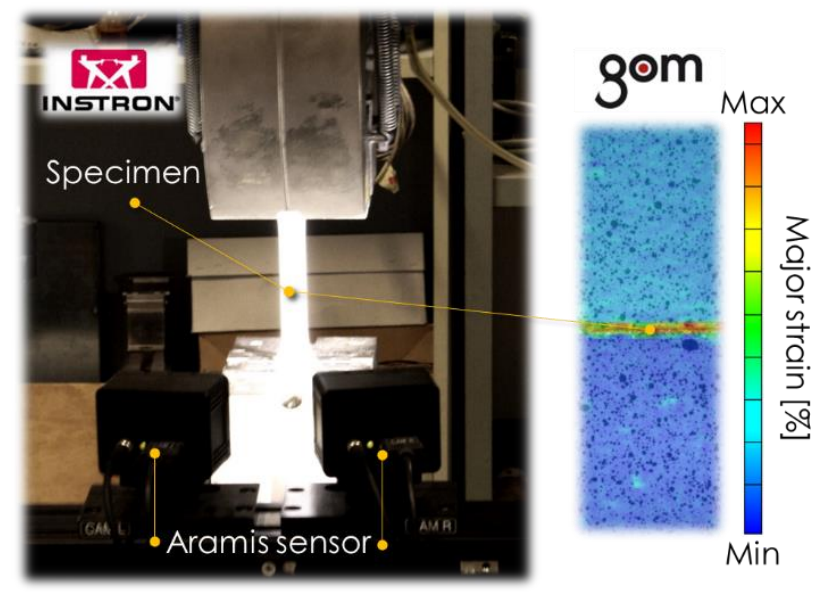

FIGURE 2. Tensile tests set up

The system discretizes the image of the surface in a cells grid, a random black speckle pattern was applied over a previously white painted matt surface; an acquisition rate of $1 \mathrm{~Hz}$ and a crosshead speed of $1 \mathrm{~mm} / \mathrm{min}$ were used for the tests. In figure 2 the Major strain field is reported as an example.

\section{METALLURGICAL CHARACTERISATION AND MICROHARDNESS}

Figure 3a shows the cross sections of the weld. The Titanium is the left side while the Aluminum is the right one. Both sides show a fused zone (FZ) and a heat-affected zone (HAZ). The fusion of the titanium 
was due to the classic keyhole welding mode while the aluminum fused for the heat that was conducted through the Al-Ti contact.

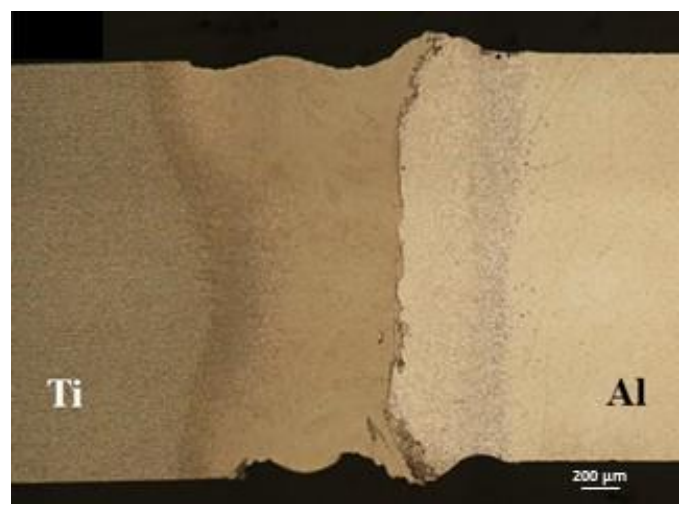

(a)

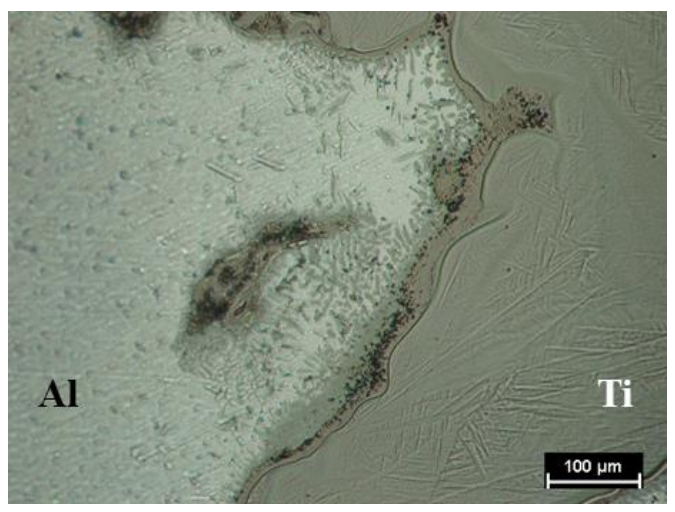

(b)

FIGURE 3. Cross section (a), magnification of the bimetallic interface (b).

The transfer of heat from $\mathrm{Ti}$ to $\mathrm{Al}$ produced the continuity between the $\mathrm{Ti}$ and the $\mathrm{Al}$ fusion zones.

Figure $3 \mathrm{~b}$ shows the magnification of the bimetallic interface. The intermetallic layer was made of $\mathrm{Ti}_{3} \mathrm{Al}_{\mathrm{l}} \mathrm{TiAl}_{3}$ compounds [18].

Figure 4 shows the microhardness profile at the mid thickness of the cross section (Vickers 0,3/15). The profile is justified by the metallurgical transformation in both sides of the weld. Martensite formed in the titanium FZ while in the ZTA the microstructure was partially martensitic. It can be observed that the microhardness of ZTA was lower than that of the FZ, which was due to the reduction of the martensitic phase. The latter diminished with the distance from the weld centerline. In the $\mathrm{Al}$ side, the microhardness value rose in the $\mathrm{FZ}$ where it happened the precipitation of hard compounds.

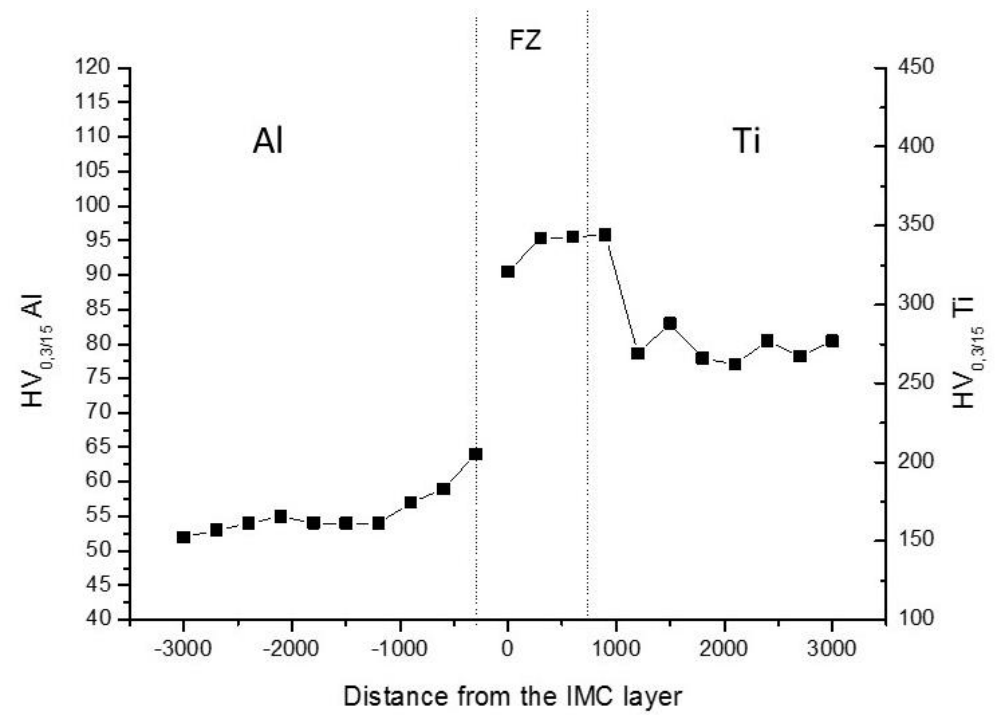


FIGURE 4. Microhardness profile of the cross section.

\section{TENSILE TEST}

Results in terms yield stress $\left(\sigma_{\mathrm{y}}\right)$, ultimate tensile strength (UTS) and the elongation at rupture have been summarized in Table 3.

TABLE 3. Mechanical and deformation properties of the joint

\begin{tabular}{ccc}
\hline oy [MPa] & UTS [MPa] & Elongation at rupture [\%] \\
\hline 103.5 & 167.9 & 5.76
\end{tabular}

In Figure 5, the fractured specimen is shown and a detail of the fracture surface is displayed. It can be noted that the rupture occurred in the welding joint.

The rupture stress was as high as $167.9 \mathrm{MPa}$ and it was quite close to the $190 \mathrm{MPa}$ ultimate tensile strength of AA6061, which was obtained by the authors.

The elongation rupture was $5.75 \%$ and it was quite lower than $15 \%$, which was again measured by the authors during a tensile test of AA6061.

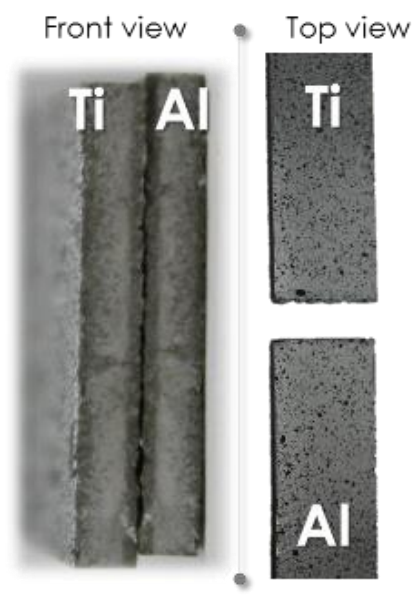

(b)

FIGURE 5. The surface of fracture in correspondence of the joint (b)

In Figure 6 the deformation behavior of the sample joint has been reported in terms of strain evolution during the test (Figure 6a) and in terms of strain distribution along the specimen (Figure 6b) 


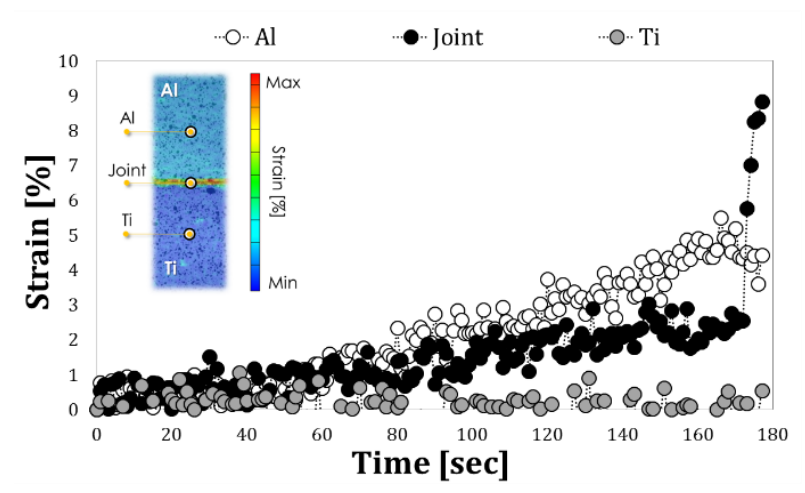

(a)

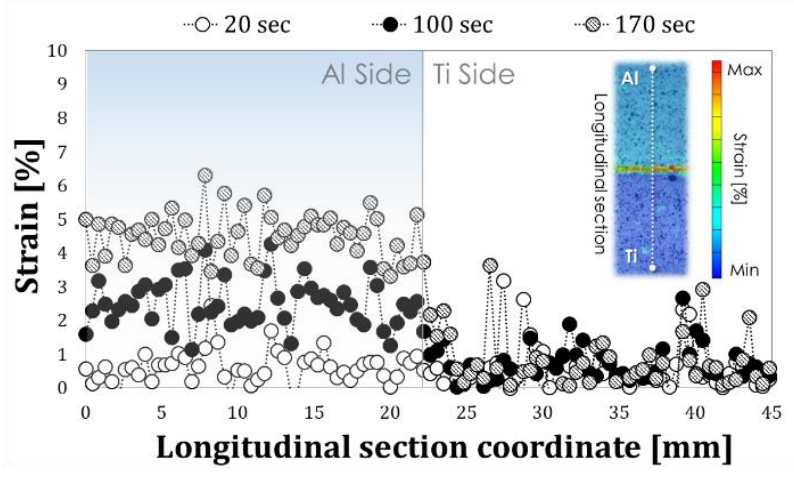

(b)

FIGURE 6. Strain evolution during the test in 3 points (a) and strain distribution along the longitudinal direction (b)

Looking at Figure 6a, it can be noted a marked strain localization in the Al material during the whole test. In addition, the strain distribution along the specimen at three time instants (Figure 6b) puts in evidence that the Ti part of the specimen is almost unloaded during the test.

\section{CONCLUSIONS}

The fiber laser welding of thin AA6061 and Ti6Al4V was performed by focusing the laser beam on the titanium alloy side. The effect of laser offset on the microstructure, mechanical properties and formation of interfacial IMC layer of the dissimilar butt joint were discussed.

It was detected the martensitic transformation in the fused zone of the titanium side and the precipitation of hard compounds in the $\mathrm{Al}$ side. The microstructural analysis exhibited the formation of an ultra-thin resistant layer of intermetallic compounds between the two metals. The metallurgy influenced the mechanical behavior of the weld. The rupture occurred in the fused zone at a tensile stress that was quite close to that of AA6061. The high strain was localization in the $\mathrm{Al}$ side while the Ti side was almost not deformed. The overall elongation was lower than that of AA6061 base metal.

Further study will focus on the effects of laser parameters on the weld strength and the dynamic plastic strain patterns of the weld.

\section{REFERENCES}

[1] K. Martinsen, S.J. Hu, B.E. Carlson. Joining of dissimilar materials. CIRP Annals Manufacturing Technology, 64, 679-699 (2015).

[2] G. Casalino. Advances in Welding Metal Alloys, Dissimilar Metals and Additively Manufactured Parts. Metals, 7, Issue 2, 1 February, Article number 32 (2017). 
[3] M. Mazar Atabaki, N. Yazdian, R. Kovacevic. Partial penetration laser-based welding of aluminum alloy (AA 5083-H32). Optik 127 (2016) 6782-6804.

[4] Atabaki, M.M., Yazdian, N., Ma, J., Kovacevic, R. High power laser welding of thick steel plates in a horizontal butt joint configuration. Optics and Laser Technology, 83, 2016, 1-12.

[5] L. Quintino, A. Costa, R. Miranda, D. Yapp, V. Kumar, C. J. Kong. Welding with high power fiber lasers-a preliminary study. Materials and design, 28, 1231-1237, (2007).

[6] S-J. Lee, H. Nakamura, Y. Kawahito, S. Katayama. Joint in Ti and Al Dissimilar Metals. Transactions of JWRI, 42, 17-21 (2013).

[7] G. Casalino, M. Mortello, P. Peyre. Yb-YAG laser offset welding of AA5754 and T40 butt joint. Journal of Materials Processing Technology, 223, 139-149 (2015).

[8] G. Casalino, P. Guglielmi, V.D. Lorusso, M. Mortello, P. Peyre, D. Sorgente. Laser offset welding of AZ31B magnesium alloy to 316 stainless steel. Journal of Materials Processing Technology, 242, 49-59 (2017).

[9] R. Khoshhal, M. Soltanieh, M. Mirjalili. Formation and growth of titanium aluminide layer at the surface of titanium sheets immersed in molten aluminum. Iranian Journal of materials science and engineering. 7, 24-31 (2010).

[10] Y. Chen, S. Chen, L. Li. Influence of interfacial reaction layer morphologies on crack initiation and propagation in Ti/Al joint by laser welding-brazing. Materials and Design. 31; 227-233 (2010).

[11]Z. Song, K. Nakata, A. Wu, J. Liao. Materials Science \& Engineering A 560; 111-120 (2013).

[12] I. Tomashchuk, P. Sallamand, A., Measson, E. Cicala, M., Duband, P. Peyre, D. Grevey. Aluminum to titanium laser welding-brazing in V-shaped groove. Journal of materials processing technology. 245; 24-36 (2017).

[13] W. V. Vaidya, M. Horstmann, V. Ventzke, B. Petrovski, M. Kocak, R. J. Kocik. Improving interfacial properties of a laser beam welded dissimilar joint of aluminium AA6056 and titanium Ti6Al4V for aeronautical applications. Mater. Sci. A 45; 6242-6254 (2010).

[14] Faraji, A.H., Moradi, M., Goodarzi, M., Colucci, P., Maletta, C. An investigation on capability of hybrid Nd:YAG laser-TIG welding technology for AA2198 Al-Li alloy. Optics and Lasers in Engineering, 96, 1 September 2017, 1-6. 
[15] D. Petkovic. Prediction of laser welding quality by computational intelligence approaches. Optik 140 (2017) 597-600.

[16] Olabi, A.G., Casalino, G., Benyounis, K.Y., Hashmi, M.S.J. An ANN and Taguchi algorithms integrated approach to the optimization of $\mathrm{CO} 2$ laser welding. Advances in Engineering Software, 37, Issue 10, October 2006, 643-648.

[17] A. G. Olabi, F. O. Alsinani, A. A. Alabdulkarim, A. Ruggiero, L. Tricarico, K. Y. Benyounis. Optimizing the CO2 laser welding process for dissimilar materials. Optics and Lasers in Engineering. 51, 7, 2013, 832-839.

[18] G. Casalino, M. Mortello. Modeling and experimental analysis of fiber laser offset welding of Al-Ti butt joints. International Journal of Advanced Manufacturing Technology, 83, 89-98 (2016). 
2017-08-31

\section{Mechanical and microstructure analysis of AA6061 and Ti6Al4V fiber laser butt weld}

Casalino, Giuseppe

Elsevier

pÿCasalino G, D Ostuni S, Guglielmi P, Leo P, Mortello M, Palumbo G, Piccininni A, Mechanical and microstructure analysis of AA6061 and Ti6Al4V fiber laser butt weld, Optik, Vol. 148,

November 2017, pp. 151-156

http://dx.doi.org/10.1016/j.jileo.2017.08.138

Downloaded from Cranfield Library Services E-Repository 